\title{
Akses Pelayanan Rumah Sakit Menjadi Faktor Dominan Kepatuhan Minum Obat pada Penderita Skizofrenia
}

\section{Access to Hospital Services Becomes a Dominant Factor in Adherence to Taking Medication in Schizophrenics Medication}

\author{
Lia Sitawati, ${ }^{1, *}$, Caroline Endah Wuryaningsih ${ }^{2}$, Dien Anshari ${ }^{3}$ \\ ${ }^{1}$ Post Graduate at Health Promotion Departement, Faculty of Public Health University of Indonesia, Indonesia \\ ${ }^{2}$ Health Promotion Departement, Faculty of Public Health University of Indonesia, Indonesia \\ \Corresponding author: liasitawati7mei@gmail.com
}

\begin{abstract}
Kata kunci:
Kepatuhan minum obat,

Akses pelayanan, Skizofrenia.

Abstrak

Latar Belakang: Skizofrenia adalah salah satu gangguan Jiwa berat. Skizofrenia diderita oleh 21 juta orang di dunia. Anggota Rumah Tangga (ART) di Indonesia yang menderita Skizofrenia/ psikosis 6,7 per mil pada 2018. Tujuan: Diketahuinya determinan kepatuhan minum obat pada penderita Skizofrenia paranoid di Poli Rawat Jalan RSJ Daerah Provinsi Lampung tahun 2019. Metode: Penelitian kuantitatif dengan desain cross sectional. Populasi adalah semua penderita skizofrenia paranoid yang berobat di tempat penelitian dengan jumlah sampel 192 orang yang diambil menggunakan teknik purposive sampling. Data dikumpulkan menggunakan teknik wawancara dengan instrumen kuesioner, kemudian dianalisis multivariat dengan uji regresi logistik berganda. Hasil: Model akhir multivariat pada tabel 3 memperlihatkan variabel yang masuk model akhir multivariat variabel yang berhubungan dengan kepatuhan minum obat adalah penghasilan $(\mathrm{OR}=4,2)$, Akses pelayanan rumah sakit (ORadjusted $=5,6$ ) dan persepsi peran Dokter (ORadjusted=4,4). Responden yang menganggap akses dari rumah ke RSJ terjangkau merupakan faktor yang paling dominan menentukan kepatuhan minum obat (ORadjusted=5,6). Simpulan: Akses pelayanan rumah sakit menjadi faktor dominan meningkatkan yang meningkatkan 5 kali kepatuhan minum obat pada penderita skizofrenia di rumah sakit Jiwa. Perlunya upaya peningkatan akses pada penderita melalui pelayanan kesehatan mental di pelayanan primer.
\end{abstract}

Keyword:

Adherence to taking

medication,

Service access,

Paranoid schizophrenia.

\begin{abstract}
Background: Schizophrenia is a severe mental disorder. Schizophrenia Aff 21 million people in the world. Household members (ART) in Indonesia who suffer from Schizophrenia / psychosis 6.7 per mile in 2018. Purpose: Know the determinants of adherence to take medication in paranoid Schizophrenia patients in Outpatient Poly Lampung Province Region in 2019. Methods: Quantitative research with cross design sectional. The population is all paranoid schizophrenics who seek treatment at the study site with 192 samples taken using a purposive sampling technique. Data were collected using an interview technique with a questionnaire instrument, then analyzed multivariate with multiple logistic regression tests. Results: There was a significant relationship between income $(O R=4.73)$, level of education $(O R=19.3)$, access $(O R=5)$, perception of family support $(O R=2.2)$, insight related to disease $(O R=3.5)$, perception of disease severity $(O R=2.6)$, perception of drug side effects $(O R=2.6)$, perception of the role of the Doctor $(O R=5.7)$ and the role of the Pharmacist $(O R=2.7)$. Conclusions: Access to hospital services is a dominant factor in increasing adherence to taking medication in schizophrenics in psychiatric hospitals. Efforts to improve access to sufferers through mental health services in primary care.
\end{abstract}




\section{Pendahuluan}

Prevalensi Skizofrenia sebesar 1\% dengan insiden sebesar $1,5 \%$ per 10.000 penduduk (Yudhantara \& Istiqomah, 2018). Skizofrenia diderita oleh 21 juta orang di dunia (WHO, 2018). Prevalensi Rumah Tangga (RT) di Indonesia dengan Anggota Rumah Tangga (ART) yang menderita Skizofrenia atau psikosis sebanyak 1,7 per mil (Kemenkes RI, 2013) meningkat menjadi 6,7 per mil pada 2018 (Kemenkes RI, 2018b).

Gangguan kejiwaan diharapkan tidak berkembang menjadi lebih serius apabila orang yang mengalaminya dapat mengatasi atau melakukan pengobatan sedini mungkin ke pusat pelayanan kesehatan atau berobat ke tenaga kesehatan yang kompeten (Kemenkes RI, 2013). Terapi gangguan Jiwa salah satunya adalah obat-obatan medis. Pengobatan dalam tahun pertama penderita sangat menentukan kesembuhan. Hampir sepertiga dari penderita yang berobat ke pelayanan kesehatan secara teratur akan sembuh total. Sepertiga lainnya dapat dikembalikan ke masyarakat walaupun masih harus sering diperiksa dan diobati, sisanya memiliki prognosis yang tidak baik, tidak dapat berfungsi didalam masyarakat (Widyantoro, 2003). Penderita yang dirawat di Rumah Sakit Jiwa dengan diagnosa skizofrenia dan mendapat pengobatan diperkirakan sebesar $25 \%$ penderita dapat sembuh, $25 \%$ dapat mandiri, 25\% membutuhkan bantuan dan 25\% lainnya tetap berada dalam kondisi berat (Keliat et al, 2011). Bunuh diri merupakan penyebab utama kematian pada penderita Skizofrenia (Kaplan \& Sadock, 2010).

Kepatuhan (adherence) adalah sejauhmana perilaku seseorang mengikuti instruksi medis (WHO, 2003). Kepatuhan terhadap pengobatan akan mengurangi dan mengontrol gejala penyakit (Keliat et al, 2011), bagian dari upaya keselamatan penderita (patient safety) untuk menghindari kekambuhan (relaps), (WHO, 2003), mengurangi resiko rehospitalisasi rate (Acosta et al, 2012), mempercepat pengurangan gejala skizofrenia, prognosis lebih baik, meningkatkan kepuasan dalam hidup penderita, mengurangi risiko timbulnya perilaku berbahaya/kekerasan/kasus kegawatdaruratan psikiatri/kondisi mental yang buruk dan mengurangi risiko bunuh diri yang lebih tinggi (Acosta et al, 2012).

Kepatuhan pengobatan juga menambah efektifitas sistem kesehatan terkait penghematan dan keluaran kesehatan yang lebih baik sebagai salah satu investasi (WHO, 2003). Badan Penyelenggara Jaminan Sosial (BPJS) kesehatan Indonesia tahun 2014 mengeluarkan dana sebesar Rp 573 miliar untuk penyakit gangguan jiwa meningkat tajam pada 2016 menjadi Rp 730 miliar. Penyakit Skizofrenia paranoid merupakan kasus yang paling banyak ditangani untuk rawat inap dan rawat jalan di pelayanan jiwa Indonesia (CNN Indonesia, 2018).

Terdapat beberapa faktor yang mempengaruhi kepatuhan minum obat penderita Skizofrenia. WHO menyatakan bahwa kepatuhan minum obat dipengaruhi oleh lima dimensi antara lain faktor sosial ekonomi, faktor terkait pengobatan (therapy), faktor terkait penderita, faktor terkait kondisi penyakit, faktor terkait tim pemberi layanan dan sistem kesehatan (WHO, 2003).

Prevalensi ganguan jiwa berat di Provinsi Lampung sebesar 1,4 per mil (Kemenkes RI, 2013), sedangkan pada 2018 meningkat menjadi 6,0 per mil. Cakupan penderita skizofrenia atau psikosis yang pernah berobat ke Rumah Sakit Jiwa atau fasilitas pelayanan kesehatan atau tenaga kesehatan sebesar 75,9\% sedangkan yang minum obat rutin dalam sebulan terakhir sebesar 42,8\% (Kemenkes RI, 2018a). Rumah Sakit Jiwa Provinsi Lampung adalah satu-satunya RS khusus jiwa di daerah Provinsi Lampung dimana Skizofrenia paranoid selalu menduduki jenis penyakit terbesar di Poli Rawat Jalan. Jumlah penderita Skizofrenia paranoid di Poli Rawat Jalan RSJ Daerah Provinsi Lampung setiap tahunnya mengalami peningkatan dimana tahun 2014 sebanyak 4.611, tahun 2015 sebanyak 7.951, tahun 2016 menjadi 9.755, tahun 2017 sebanyak 10.928 dan pada 2018 sebanyak 11.025 (Rumah Sakit Jiwa Provinsi Lampung, 2018). Angka kepatuhan minum obat di Rumah Sakit 
Jiwa Daerah Provinsi Lampung tahun 2003 sebesar 40,6\% (Widyantoro, 2003) dan pada tahun 2013 sebesar 28,7\% (Noviria, Triyoso, \& Yanti, 2013).

Faktor yang berhubungan dengan kepatuhan adalah umur, penghasilan, wawasan terkait penyakit (Chaudhari et al, 2017), kemudahan transportasi/akses (Widyantoro, 2003), efek samping pengobatan yang dirasakan lebih sedikit (Eticha et al., 2015), keparahan penyakit, faktor pengobatan, lingkungan keluarga dimana faktor yang paling dominan mempengaruhi kepatuhan adalah lingkungan keluarga (Rawa, Rattu, \& Posangi, 2017). Artikel ini merupakan hasil penelitian dengan tujuan untuk mengetahui determinan seperti faktor sosial ekonomi (umur, penghasilan, tingkat pendidikan, akses ke RSJ, persepsi dukungan keluarga), faktor terkait pasien (wawasan terkait penyakit), faktor kondisi penyakit (persepsi keparahan penyakit), faktor pengobatan (efek samping obat), faktor pemberi layanan (persepsi peran Dokter, persepsi peran Apoteker) dengan kepatuhan minum obat pada penderita skizofrenia paranoid di Poli Rawat Jalan Rumah Sakit Jiwa Daerah Provinsi Lampung tahun 2019.

\section{Metode}

Penelitian ini menggunakan desain kuantitatif dengan rancangan cross sectional. Rancangan penelitian digunakan untuk mengetahui determinan yang dominan kepatuhan minum obat pada penderita skizofrenia paranoid di Poli Rawat Jalan Rumah Sakit Jiwa Daerah Provinsi Lampung tahun 2019.

Populasi adalah penderita skizofrenia paranoid yang berobat di poliklinik Rawat Jalan tahun 2018 dengan diagnosa skizofrenia paranoid berjumlah 10.928. Jumlah sampel menggunakan rumus besar sampel uji hipotesis beda proporsi, didapat besar sampel minimal untuk penelitian ini menjadi sebanyak 192 orang responden. Kriteria inklusi sampel adalah penderita yang telah lolos skrining oleh Dokter Spesialis Kedokteran Jiwa atau Dokter Umum yang bertugas di poli rawat jalan, hanya mendapatkan obat oral dan dinyatakan Dokter stabil untuk dilakukan wawancara, minimal sudah 1 kali mendapatkan pengobatan rawat jalan baik secara berturut-turut atau tidak, penderita yang menerima sendiri secara langsung obat yang diserahkan Apoteker di instalasi farmasi dan berumur $\geq 17$ tahun. Kriteria ekslusi sampel adalah penderita yang mengalami tunarungu, tunawicara, tunalaras (cacat suara dan nada), tunagrahita (disabilitas mental), memiliki penyakit penyerta seperti stroke, Diabetes Melitus, mengalami penurunan penglihatan namun belum memakai alat bantu lihat sehingga membuat pertanyaan tentang efek samping obat menjadi bias. Penderita perempuan yang sudah mengalami menopouse, penderita pria yang mengalami andropouse dan penderita yang tidak bisa berbahasa Indonesia .

Cara pengambilan sampel dilakukan dengan menggunakan teknik purposive sampling yang dilakukan oleh Dokter Umum yang bertugas di Poli Rawat Jalan dengan mempertimbangkan kestabilan pasien Skizofrenia secara klinis. Instrumen penelitian, kepatuhan diukur menggunakan Medication Adherence Rating Scale (MARS). Akses diukur menggunakan Kuesioner Riskesdas, 2018 (Kemenkes RI, 2018c). Persepsi dukungan keluarga/pendamping utama berdasarkan (Keliat et al, 2011). Wawasan terkait penyakit diukur menggunakan Insight treatment attitude questionare (ITAQ) McEvoy et al (Keefe, 2012), persepsi keparahan penyakit menggunakan Brief Psychiatric Rating Scale (BPRS)- 24-item version Ventura (Keefe, 2012), Efek samping obat menggunakan instrumen The Glasgow Antipsychotic side effect scale (GASS) Wadell \& Taylor (Keefe, 2012), persepsi peran Dokter dan Apoteker diukur menggunakan (Badan Pengawas Obat dan Makan, 2018). Uji coba kuesioner dilakukan pada 30 orang penderita Skizofrenia paranoid di Rumah Sakit Jiwa Daerah Provinsi Lampung menunjukan semua butir pertanyaan valid dan reliabel. Peneliti sudah mendapatkan surat Lolos Kaji etik dari Komisi Etik Riset dan Pengabdian Kesehatan Masyarakat Fakultas Kesehatan Masyarakat Universitas Indonesia Pada Tanggal 18 Maret 2019 dengan Nomor 
119/UN2.F10/PPM.00.02/2019. Data yang telah dikumpulkan dilakukan analisis secara bertahap, dimulai dengan analisis univariat, analisis bivariat dan analisis multivariat. Analisis multivariat menggunakan uji regresi logistik berganda.

\section{Hasil}

\section{Gambaran responden}

Hasil analisis univariat pada tabel 1 menunjukkan gambaran responden atau variabel yang berisiko yang diikutkan dalam analisis data penelitian.

Tabel 1.

Gambaran penderita skizofrenia di RSJ Provinsi Lampung

\begin{tabular}{lcc}
\hline \multicolumn{1}{c}{ Variabel } & Frequency & \% \\
\hline Usia (dewasa >30 tahun) & 135 & 70,3 \\
Pendapatan (< upah minimum Provinsi Lampung 2019 Rp 2.240.646) & 158 & 82,3 \\
Pendidikan (level bawah-tidak sekolah-tamat SD-tamat SMP) & 90 & 46,9 \\
Akses dari rumah ke RSJ (Terjangkau) & 141 & 73,4 \\
Persepsi dukungan keluarga (tinggi) & 97 & 50,5 \\
Wawasan terkait penyakit yang diderita (baik) & 135 & 70,3 \\
Persepsi : keparahan penyakit (tidak ada gejala psikotik yang dirasakan) & 118 & 61,5 \\
Persepsi : efek samping obat (tidak ada) & 105 & 54,7 \\
Persepsi : Peran Dokter (rendah) & 129 & 67,25 \\
Persepsi : Peran Apoteker (tinggi) & 154 & 80,2 \\
Kepatuhan pengobatan (patuh) & 98 & 51,0 \\
\hline
\end{tabular}

\section{Seleksi bivariat untuk kandidat multivariat}

Tahapan awal analisis bivariat pada tabel 2 melakukan analisis bivariat seleksi variabel yang dimasukkan kandidat multivariat dengan regresi logistik berganda. Variabel yang memiliki nilai $\mathrm{p}<$ 0,25 dimasukkan menjadi variabel kandidat yang masuk dalam analisis multivariat. Rangkuman hasil seleksi kandidat multivariat dapat dilihat pada tabel 3.

Hasil seleksi bivariat semua variabel menghasilkan $\mathrm{p}$ value $<0,25$ hanya umur yang $\mathrm{p}$ valuenya $>0,25$, namun variabel umur tetap dianalisis ke multivariat karena secara substansi umur merupakan variabel yang sangat penting berhubungan dengan kepatuhan minum obat. Selanjutnya kesepuluh variabel yang lolos seleksi bivariat dilakukan analisis secara bersama-sama ke dalam model, lalu dilakukan permodelan sehingga didapatkan model akhir multivariat (tabel 4).

\section{Model akhir multivariat}

Model akhir multivariat pada tabel 3 memperlihatkan variabel yang masuk model akhir multivariat variabel yang berhubungan dengan kepatuhan minum obat adalah penghasilan $(\mathrm{OR}=4,2)$, Akses pelayanan rumah sakit (ORadjusted $=5,6$ ) dan persepsi peran Dokter (ORadjusted $=4,4$ ). Responden yang menganggap akses dari rumah ke RSJ terjangkau merupakan faktor yang paling dominan menentukan kepatuhan minum obat (ORadjusted $=5,6$ ). Keterjangkauan akses rumah sakit atau pelayanan kesehatan meningkatkan 6 kali penderita Skizofrenia kepatuhan minum obat.

\section{Pembahasan}

\section{Hubungan umur dengan kepatuhan minum obat}

Hasil penelitian mendapatkan tidak terdapat hubungan yang signifikan antara umur dengan kepatuhan minum obat ( $p$-value 0,615$)$. Hipotesis tidak terbukti karena terkait keterbatasan penelitian, karena rancangan saampel menggunakan non random sampling dengan teknik purposive sampling. Hendaknya monitoring khusus pada responden dengan usia dewasa muda mengingat semakin muda 
usia onset terkena penyakit maka prognosis akan semakin buruk. Bagi responden dengan usia dewasa tua >30 diharapkan tetap melanjutkan pengobatan, agar pasien dapat hidup bermartabat, melakukan aktivitas hidup sehari-hari secara mandiri.

Tabel 2.

Analisis bivariat hubungan antara variabel dengan kepatuhan penderita skizofrenia

\begin{tabular}{|c|c|c|c|c|c|}
\hline \multirow[b]{2}{*}{ Variabel } & \multicolumn{2}{|c|}{ Kepatuhan } & \multirow{2}{*}{$\begin{array}{l}\text { Total } \\
\text { n }(\%)\end{array}$} & \multirow{2}{*}{$\begin{array}{c}P \\
\text { value }\end{array}$} & \multirow[b]{2}{*}{ OR $(95 \% C I)$} \\
\hline & $\begin{array}{l}\text { Patuh } \\
\text { n }(\%)\end{array}$ & $\begin{array}{c}\text { Tidak patuh } \\
\text { n }(\%)\end{array}$ & & & \\
\hline \multicolumn{6}{|l|}{ Usia } \\
\hline Dewasa $>30$ tahun & $71(52,6)$ & $64(47,4)$ & $135(100)$ & 0,615 & $1,2(0,6-2,2)$ \\
\hline Muda $\leq 30$ tahun & $27(47,4)$ & $30(52,6)$ & $57(100)$ & & \\
\hline \multicolumn{6}{|l|}{ Penghasilan } \\
\hline$\geq$ UMP Lampung & $27(79,4)$ & $7(20,6)$ & $34(100)$ & 0,001 & $4,7(1,9-11,4)$ \\
\hline$<$ UMP Lampung & $71(44,9 \%)$ & $87(55,1)$ & $158(100)$ & & \\
\hline \multicolumn{6}{|l|}{ Tingkat pendidikan } \\
\hline Tinggi (Diploma- Sarjana) & $29(93,5)$ & $2(6,5)$ & $31(100)$ & 0,001 & - \\
\hline Menengah (SMA) & $31(43,7)$ & $40(56,3)$ & $71(100)$ & & \\
\hline Dasar (SMP-SD) & $38(42,2)$ & $52(57,8)$ & $90(100)$ & & \\
\hline \multicolumn{6}{|l|}{ Akses ke RSJ } \\
\hline Terjangkau & $86(61,0)$ & $55(39,0)$ & $141(100)$ & 0,001 & $5,0(2,4-10,5)$ \\
\hline Tidak terjangkau & $12(23,5)$ & $39(76,5)$ & $51(100)$ & & \\
\hline \multicolumn{6}{|l|}{ Persepsi dukungan } \\
\hline keluarga & $59(60,8)$ & $38(39,2)$ & $97(100)$ & 0,009 & $2,2(1,2-3,9)$ \\
\hline Tinggi & $39(41,1)$ & $56(58,9)$ & $95(100)$ & & \\
\hline \multicolumn{6}{|l|}{ Rendah } \\
\hline \multicolumn{6}{|l|}{ Insight into illness } \\
\hline Baik & $81(60)$ & $54(40,0)$ & $135(100)$ & 0,001 & $3.5(1,8-6,8)$ \\
\hline Buruk & $17(29,8)$ & $40(70,2)$ & $57(100)$ & & \\
\hline keparahan & & & & & \\
\hline penyakit & $71(60,2)$ & $47(39,8)$ & $118(100)$ & 0,001 & $2,6(1,4-4,7)$ \\
\hline Tidak & $27(36,5)$ & $47(63,5)$ & $74(100)$ & & \\
\hline \multicolumn{6}{|l|}{ Gejala ringan-berat } \\
\hline \multicolumn{6}{|l|}{ Persepsi efek samping } \\
\hline Tidak ada & $65(61,9)$ & $40(38,1)$ & $105(100)$ & 0,002 & $2,6(1,4-4,7)$ \\
\hline Ada (Ringan-Berat) & $33(37,9)$ & $54(62,1)$ & $87(100)$ & & \\
\hline \multicolumn{6}{|l|}{ Persepsi peran dokter } \\
\hline Tinggi & $49(77,8)$ & $14(22,2)$ & $63(100)$ & 0,000 & $5,7(2,8-11,4)$ \\
\hline Rendah & $49(38,0)$ & $80(62,0)$ & $129(100)$ & & \\
\hline \multicolumn{6}{|l|}{ Persepsi peran apoteker } \\
\hline Tinggi & $86(55,8)$ & $68(44,2)$ & $154(100)$ & 0,012 & $2,7(1,2-5,8)$ \\
\hline Rendah & $12(31,6)$ & $26(68,4)$ & $38(100)$ & & \\
\hline
\end{tabular}

Tabel 3.

Hasil seleksi bivariat variabel yang masuk kandidat multivariat

\begin{tabular}{lcl}
\hline \multicolumn{1}{c}{ Variabel } & p-value & \multicolumn{1}{c}{ Keterangan } \\
\hline Umur & 0,508 & Bukan kandidat \\
Penghasilan & 0,002 & Kandidat multivariat \\
Tingkat pendidikan & 0,000 & Kandidat multivariat \\
Akses ke RSJ & 0,000 & Kandidat multivariat \\
Persepsi dukungan keluarga & 0,006 & Kandidat multivariat \\
Wawasan terkait penyakit & 0,020 & Kandidat multivariat \\
Persepsi keparahan penyakit & 0,001 & Kandidat multivariat \\
Persepsi efek samping & 0,001 & Kandidat multivariat \\
Persepsi peran Dokter & 0,000 & Kandidat multivariat \\
Persepsi peran Apoteker & 0,007 & Kandidat multivariat \\
\hline
\end{tabular}


Tabel 3.

Analisis multivariat model akhir kepatuhan

\begin{tabular}{|c|c|c|c|c|c|}
\hline Independen Variabel & B & P-value & OR & \multicolumn{2}{|c|}{$95 \% C I$} \\
\hline Penghasilan & 1,447 & 0,006 & 4,248 & 1,507 & 11,973 \\
\hline Akses pelayanan rumah sakit terjangkau & 1,728 & 0,000 & 5,631 & 2,465 & 12,864 \\
\hline Persepsi peran Dokter & 1,482 & 0,000 & 4,401 & 2,077 & 9,328 \\
\hline
\end{tabular}

\section{Hubungan penghasilan dengan kepatuhan minum obat}

Hasil penelitian mendapatkan hubungan yang signifikan antara penghasilan dengan kepatuhan minum obat (hipotesis terbukti) sehingga dapat dikatakan bahwa responden dengan penghasilan lebih atau sama dengan UMP memiliki peluang 4,7 kali lebih tinggi untuk patuh minum obat dibandingkan dengan responden yang memiliki penghasilan kurang dari UMP. Hasil penelitian ini serupa dengan hasil penelitian Chaudhari et al (2017) yang menyatakan ada hubungan yang signifikan antara penghasilan dengan kepatuhan minum obat.

Hendaknya bagi responden yang tidak bekerja dan memiliki ketrampilan dapat dilakukan upaya kerjasama dari pihak RS dengan perusahan tertentu sebagai upaya Corporate Social Responsibility. Untuk penderita yang tidak bekerja dapat diberikan bantuan transportasi yang berasal dari dana desa bidang kesehatan.

\section{Hubungan tingkat pendidikan dengan kepatuhan minum obat}

Hasil penelitian mendapatkan ada hubungan yang signifikan antara tingkat pendidikan dengan kepatuhan minum obat (Hipotesis gagal ditolak) sehingga dapat dikatakan bahwa responden dengan tingkat pendidikan tinggi (sarjana) memiliki peluang 19,3 kali lebih tinggi untuk patuh minum obat dibandingkan dengan responden yang memiliki tingkat pendidikan menengah-dasar. Hendaknya petugas memberikan informasi untuk responden yang berpendidikan tinggi terkait sumber informasi daring, laring terkait kesehatan Jiwa. Mengaktifkan kembali website, seperti untuk RSJ Provinsi Lampung mengaktifkan http://RSJdprovlampung.com/ agar lebih informatif dan bermanfaat. Bagi Responden yang berpendidikan rendah rumah sakit dapat meminta nomor handphone pasien dan keluarga pasien agar dapat diberikan sms edukasi kesehatan terkait penyakit dan pengobatan Skizofrenia paranoid.

\section{Hubungan akses ke RS Jiwa dengan kepatuhan minum obat}

Hasil penelitian mendapatkan ada hubungan yang signifikan antara akses ke RSJ dengan kepatuhan minum obat sehingga dapat dikatakan bahwa responden dengan akses ke RSJ terjangkau memiliki peluang 5 kali lebih tinggi untuk patuh minum obat dibandingkan dengan responden yang memiliki akses tidak terjangkau. Hasil penelitian ini serupa dengan hasil penelitian Widyantoro (2003) yang menyatakan kemudahan transportasi/akses adalah variabel yang berhubungan signifikan dengan kepatuhan minum obat.

Hendaknya bagi responden melengkapi data kependudukan responden, seperti e-KTP sekalipun penderita Skizofrenia sebagai warga negara berhak ikut dalam program BPJS dan mendapatkan hak memiliki KTP. Untuk responden yang kategori tidak mampu agar mengajukan permohonan BPJS PBI berjenjang dari kepala desa untuk diteruskan ke kantor BPJS Cabang lokasi masing-masing.

\section{Hubungan persepsi dukungan keluarga dengan dengan kepatuhan minum obat}

Hasil penelitian mendapatkan ada hubungan yang signifikan antara persepsi dukungan keluarga dengan kepatuhan minum obat sehingga dapat dikatakan bahwa responden dengan persepsi dukungan keluarga tinggi memiliki peluang 2,2 kali lebih tinggi untuk patuh minum obat 
dibandingkan dengan responden yang memiliki persepsi dukungan keluarga rendah. Hasil penelitian ini serupa dengan hasil penelitian Christiawati \& Murti, (2012) yang menyebutkan ada hubungan dukungan keluarga dengan kepatuhan minum obat.

Hendaknya dilakukan terapi berorientasi keluarga dapat dijalankan untuk mengidentifikasi dan penghindaran situasi yang berpotensi menyusahkan, keluarga dapat memahami dan mempelajari Skizofrenia, strategi mengatasi masalah, mengurangi stess dan menuju reintegrasi bertahap pasien dengan kehidupan sehari-hari.

\section{Hubungan wawasan terkait penyakit dengan kepatuhan minum obat}

Hasil penelitian mendapatkan ada hubungan yang signifikan antara wawasan terkait penyakit dengan kepatuhan minum obat sehingga dapat dikatakan bahwa responden dengan wawasan terkait penyakit baik memiliki peluang 18,3 kali lebih tinggi untuk patuh minum obat dibandingkan dengan responden yang memiliki wawasan terkait penyakit buruk. Hasil penelitian ini serupa dengan hasil penelitian Chaudhari et al (2017) yang mendapatkan hasil ada hubungan signifikan antara wawasan terkait penyakit ( p 0,001) dengan kepatuhan minum obat. Penelitian Bayle et al (2015) menyebutkan bahwa terdapat hubungan wawasan terkait penyakit dengan kepatuhan. Hendaknya petugas melakukan terapi perilaku kognitif (Cognitif Behavior Therapy) pada responden untuk memperbaiki distorsi kognitif (kesalahan logika dalam berfikir), mengurangi distraktibilitas (gangguan pemusatan pikiran), mengoreksi kesalahan daya nilai terkait perilaku patuh minum obat untuk mencari dan menemukan bersama hal-hal positif yang terjadi jika patuh minum obat.

\section{Hubungan persepsi keparahan penyakit dengan kepatuhan minum obat}

Hasil penelitian mendapatkan ada hubungan yang signifikan antara persepsi keparahan penyakit dengan kepatuhan minum obat sehingga dapat dikatakan bahwa responden tanpa gejala psikotik yang dirasakan memiliki peluang 10,2 kali lebih tinggi untuk patuh minum obat dibandingkan dengan responden yang memiliki gejala psikotik ringan-berat. Hasil penelitian ini serupa dengan hasil penelitian Rawa, Rattu, \& Posangi (2017) menyatakan Keparahan penyakit (p 0,033) berhubungan dengan kepatuhan minum obat. Penelitian (Bayle, Tessier, Bouju, \& Misdrahi, 2015) menyebutkan bahwa terdapat hubungan antara keparahan penyakit dengan kepatuhan minum obat. Sekalipun tidak ada gejala penyakit yang dirasakan bukan berarti pasien tidak membutuhkan bantuan obat-obatan lagi, namun penderita ada dalam kondisi stabil dengan obat-obatan. Edukasi kepada pasien terkait gejala positif, negatif yang mungkin muncul berkaitan dengan pembicaraan, halusinasi, waham/delusi, niat bunuh diri agar pasien dapat mengenali gejala yang dirasakan dan cara mengelola, mengatasi dan melakukan penyesuaikan serta berkonsultasi pada Dokter Spesialis Keokteran Jiwa terkait gejala keparahan.

\section{Hubungan persepsi efek samping obat dengan kepatuhan minum obat}

Hasil penelitian mendapatkan ada hubungan yang signifikan antara persepsi efek samping obat dengan kepatuhan minum obat sehingga dapat dikatakan bahwa responden yang mempersepsikan tidak ada efek samping obat yang dirasakan memiliki peluang 2,6 kali lebih tinggi untuk patuh minum obat dibandingkan dengan responden yang memiliki gejala psikotik ringan-berat. Hasil penelitian ini serupa dengan Penelitian Eticha et al (2015) menyatakan efek samping pengobatan yang dirasakan lebih sedikit (OR 0,97), dan penelitian (Rawa et al., 2017) menyatakan faktor pengobatan (p 0,002) $O R=7$ berhubungan dengan kepatuhan minum obat. Begitu pula hasil penelitian DiBonaventura et al (2012) yang mendapatkan hasil ada hubungan gejala ekstapiramidal/agitasi $p$-value $=0,000$, sedasi/kognisi $p$-value $=0,033$, prolaktin/endoktin $p$-value $=0,03$ dan efek samping metabolik $p$ value $=0,00$. 
Hendaknya rumah sakit menyediakan layanan konseling, atau nomor hotline terkait dengan keluhan efek samping yang dirasakan jika dirasa mengganggu akan dianjurkan untuk berkonsultasi dan memeriksakan diri ke dokter sebelum memutuskan untuk berhenti minum obat.mengadvokasi pasien untuk berani bertanya kepada dokter yang bertugas terkait penyakitnya, efek samping yang dirasakan untuk disampaikan. Terkait efek samping adalah kelebihan berat badan hendaknya dilakukan edukasi terkait pentingnya aktivitas fisik.

\section{Hubungan persepsi peran dokter dengan kepatuhan minum obat}

Hasil penelitian mendapatkan ada hubungan yang signifikan antara persepsi peran Dokter dengan kepatuhan minum obat sehingga dapat dikatakan bahwa responden yang mempersepsikan peran Dokter tinggi memiliki peluang 5,7 kali lebih tinggi untuk patuh minum obat dibandingkan dengan responden yang mempersepsikan peran Dokter rendah. Hasil penelitian ini serupa dengan hasil penelitian Bayle et al (2015) yang menyebutkan bahwa therapeutic alliance (kerjasama antara tenaga kesehatan-pasien) berhubungan dengan kepatuhan dengan p-value 0,000. Hendaknya Rumah Sakit menambah jumlah sumber daya Dokter Spesialis Kedokteran Jiwa dan Dokter Umum yang bertugas di Poli Rawat jalan agar setiap pasien dapat berkonsultasi lebih intens. Rumah Sakit juga sebaiknya menyediakan tenaga Penyuluh Kesehatan Rumah Sakit untuk membantu pelaksanaan promosi kesehatan.

\section{Hubungan persepsi peran ppoteker dengan kepatuhan minum obat}

Ada hubungan yang signifikan antara persepsi peran Apoteker dengan kepatuhan minum obat sehingga dapat dikatakan bahwa responden yang mempersepsikan peran Apoteker tinggi memiliki peluang 2,7 kali lebih tinggi untuk patuh minum obat dibandingkan dengan responden yang mempersepsikan peran Apoteker rendah. Hasil penelitian ini serupa dengan penelitian Mishra et al (2017) yang mendapatkan hasil terdapat hubungan antara peran Apoteker dan kolaborasi pendidikan pada pasien dengan kepatuhan dengan $\mathrm{p}=0,001$. Begitu pula penelitian Stuhec \& Gorenc (2018) yang menyatakan bahwa penerimaan akan rekomendasi dari seorang farmasi klinis berpengaruh terhadap kepatuhan dalam terapi antipsikotik $(\mathrm{p}=0,041)$. Hendaknya loket penyerahan obat dibuat tanpa sekat dan diberi kursi agar Apoteker bisa menjelaskan secara seksama dan responden bisa mengajukan pertanyaan jika kurang jelas. Saat menjelaskan obat sebaiknya tidak menggunakan pengeras suara karena akan melanggar privacy responden. Dapat juga pasien diberikan leaflet yang dapat dibaca dan dibawa pulang. Pemasangan tv untuk menayangkan video edukasi diruang tunggu, poster, banner terkait Gema Cermat, kepatuhan minum obat, sebagai wujud bina suasana menghiupkan upaya kepatuhan minum obat di lingkup instalasi farmasi RSJ Daerah Provinsi Lampung.

\section{Akses pelayanan rumah sakit menjadi faktor dominan kepatuhan minum obat}

Hasil uji multivariat dari penelitian ini menemukan determinan kepatuhan minum obat adalah penghasilan, akses ke RSJ dan persepsi peran Dokter. Variabel yang paling dominan adalah akses ke RSJ, hal ini menunjukan bahwa responden yang menganggap akses dari rumah ke RSJ terjangkau merupakan faktor yang paling dominan menentukan kepatuhan minum obat $(\mathrm{OR}=5,6)$. Sasaran pembangunankesehatan Jiwa pada RPJMN 2015-2019 adalah Meningkatnya Mutu dan Akses Pelayanan Kesehatan Jiwa dan NAPZA diantaranya adalah jumlah kabupaten/Kota yang memiliki Puskesmas yang menyelenggarakan upaya kesehatan Jiwa serta persentasi RS umum rujukan yang menyelenggarakan pelayanan kesehatan Jiwa/psikiatri (Kemenkes RI, 2014). Provinsi Lampung tidak memiliki puskesmas yang menyelenggarakan pelayanan kesehatan Jiwa. Akses terhadap pelayanan kesehatan Jiwa hendaknya pelayanan kesehatan Jiwa berintegrasi dengan pelayanan primer karena beban biaya dan psikis pada penderita dan keluarganya pelayanna kesehatan Jiwa di pelayanan primer 
jauh lebih murah daipada biaya akses di rumah sakit, mengingat di Indonesia pelayanan kesehatan Jiwa diselenggarakan hanya ditingkat primer atau tersier dikarenanakan ketidaksiapan pemberi pelayanan di RSU Kab/ota menyebabkan hampir semua pasien gangguan Jiwa di rujuk ke RSJ.

Hendaknya dilakukan reformasi pelayanan kesehatan Jiwa dengan menyediakan pelayanan kesehatan Jiwa di Puskesmas dan RSU kabupaten/Kota yang didukung oleh tenaga medis spesialis kedokteran Jiwa. Hendaknya dilakukan pelatihan terkait penatalaksanaaan gangguan Jiwa bagi tenaga Dokter Umum sebagai alternatif sumber daya manusia kesehatan Jiwa. Hendaknya dilakukan kerjasama antara Kementerian Kesehatan dengan Institusi Kesehatan Pendidikan Kedokteran Spesialis Jiwa untuk menjawab kesenjangan antara kebutuhan dan ketersediaan tenaga Dokter.

\section{Simpulan dan saran}

Hasil penelitian memperlihatkan model akhir multivariat variabel yang berhubungan dengan kepatuhan minum obat adalah penghasilan (ORadjusted $=4,2$ ), Akses pelayanan rumah sakit (ORadjusted $=5,6$ ) dan persepsi peran Dokter (ORadjusted $=4,4$ ). Responden yang menganggap akses dari rumah ke RSJ terjangkau merupakan faktor yang paling dominan menentukan kepatuhan minum obat (ORadjusted=5,6). Keterjangkauan akses rumah sakit atau pelayanan kesehatan meningkatkan lima kali penderita Skizofrenia kepatuhan minum obat, kemudian faktor peran persepsi Dokter dan pendapatan keluarga. Perlunya upaya penyebaran keterjangkauan pelayanan untuk masalah kesehatan jiwa. Hendaknya pelayanan kesehatan Jiwa berintegrasi dengan pelayanan primer, diadakan puskesmas percontohan di Lampung yang melaksanakan pelayanan kesehatan Jiwa serta RS umum di Lampung yang menyelenggarakan pelayanan kesehatan Jiwa.

\section{Referensi}

Acosta et al. (2012). Medication adherence in schizophrenia. World Journal Of Psychiatry, 2(5), 74-78.

Badan Pengawas Obat dan Makan. (2018). Buku informatorium obat Nasional Indonesia (IONI). Retrieved November 12, 2018, from Pusat Informasi Obat Nasional website: http://pionas.pom.go.id/ioni

Bayle, F. J., Tessier, A., Bouju, S., \& Misdrahi, D. (2015). Medication adherence in patients with psychotic disorders: An observational survey involving patients before they switch to long-acting injectable risperidone. Patient Preference and Adherence, 9, 1333-1341. Retrieved from https://www.dovepress.com/getfile.php2015416363

Chaudhari et al. (2017). Evaluation of treatment adherence in outpatients with schizoprenia. Industrial Psychiatry Journal, 26(2), 195-201. https://doi.org/10.4103/ipj.ipj

CNN Indonesia. (2018). Penyakit kesehatan kiwa dalam perlindungan BPJS. Retrieved December 19, 2018, from https://www.cnnindonesia.com/gaya-hidup/20181012193101s

Emsley, R., Chiliza, B., Asmal, L., \& Harvey, B. H. (2013). The nature of relapse in schizophrenia. BMC Psychiatry, 13, 1-9. Retrieved from http://www.embase.com/search/. http://dx.doi.org/10.1186/1471244X-13-50

Eticha, T., Teklu, A., Ali, D., Solomon, G., Alemayehu, A., Tareke, M., ... Unit, P. (2015). Antipsychotic medication non-adherence among schizophrenia patients in Central Ethiopia. 1-11. https://doi.org/10.1371/journal.pone.0120560

Kaplan \& Sadock. (2010). Buku ajar psikiatri Klinis (Edisi 2; H. Muttaqin \& R. N. E. Sihombing, Eds.). Jakarta: EGC.

Keefe, R. (2012). Guide to assessment scales in schizophrenia (3rd Editio). London, United Kingdom: Springer Healthcare.

Keliat et al. (2011). Manajemen kasus gangguan jiwa CMHN (Intermediate Course). Jakarta: EGC.

Kemenkes RI. (2013). Riset kesehatan dasar (Riskesdas). Jakarta.

Kemenkes RI. (2014). Rencana aksi kegiatan tahun 2014-2019. Direktorat Bina Kesehatan Jiwa. 
Akses Pelayanan Rumah Sakit Menjadi Faktor Dominan Kepatuhan Minum Obat pada Penderita Skizofrenia ...

Lia Sitawati, Caroline Endah Wuryaningsih, Dien Anshari

Jurnal Kesehatan Metro Sai Wawai. 12 (1) 2019. E-ISSN 2657-1390. P-ISSN 19779-469X

https://doi.org/.1037//0033-2909.I26.1.78

Kemenkes RI. (2018a). Hasil utama Riset Kesehatan Dasar (Riskesdas) 2018. Kemenkes RI. Jakarta.

Kemenkes RI. (2018b). Laporan Nasional Riset Kesehatan Dasar (Riskesdas) 2018. Jakarta.

Kemenkes RI. (2018c). Pengisian kuesioner Riset Kesehatan Dasar (Riskesdas) 2018.

Kemenkes RI. (2018d). Permenkes No 44 Tahun 2018 tentang penyelenggaraan promosi kesehatan Rumah Sakit. https://doi.org/10.22201/fq.18708404e.2004.3.66178

Noviria, Triyoso, \& Yanti, L. (2013). Hubungan dukungan keluarga dengan kunjungan kontrol pasien jiwa Skizofrenia di Rawat Jalan di RSJ Provinsi Lampung Tahun 2013. Jurnal Kesehatan Holistik, 8(2), 76-81. Retrieved from http://malahayati.ac.id/wp-content/uploads/2016/09/6.-Masnona_Triyoso_Lika.pdf

Rawa, F., Rattu, A. J. M., \& Posangi, J. (2017). Faktor-Faktor yang berhubungan dengan kepatuhan minum obat pada penderita skizofrenia di Rumah Sakit Jiwa Prof.DR.V.L. Ratumbuysang Provinsi Sulawesi Utara. Jurnal IKMAS, 1-14. Retrieved from http://www.ejournalhealth.com/index.php

Rumah Sakit Jiwa Provinsi Lampung. (2018). Data kunjungan pasien Rumah Sakit Jiwa Provinsi Lampung.

WHO. (2003). Adherence to long-term therapies, Evidence for Action. Genewa.

WHO. (2017). International statistical classification of diseases and related health problems 10th Revision (ICD10)-WHO Version for ;2016. Retrieved December 8, 2018, from https://icd.who.int/browse10/2016/en\#/F20

WHO. (2018). Fact sheet: schizophrenia. Retrieved from World Health Organization website: http://www.who.int/en/news-room/fact-sheets/detail/schizophrenia

Widyantoro, A. (2003). Faktor-faktor yang berhubungan dengan kepatuhan keluarga penderita skizofrenia membawa keluarganya yang sakit berobat jalan di rumah sakit Jiwa Provinsi Lampung tahun 2003. Tesis Universitas Indonesia. Retrieved from http://www.lontar.ui.ac.id/file?file=pdf/abstrak/id_abstrak74084.pdf

Yudhantara, D. S., \& Istiqomah, R. (2018). Sinopsis skizofrenia untuk Mahasiswa Kedokteran. Malang: UB Press. 